\title{
Impact Force Evaluation of the Derailment Containment Wall for High-Speed Train through a Collision Simulation
}

\author{
Hyun-Ung Bae $\mathbb{D}^{1},{ }^{1}$ Kyung-Min Yun $\mathbb{D}^{1},{ }^{1}$ Jiho Moon $\mathbb{D}^{2},{ }^{2}$ and Nam-Hyoung Lim $\mathbb{D}^{1}$ \\ ${ }^{1}$ Department of Civil Engineering, Chungnam National University, 34134 Daejeon, Republic of Korea \\ ${ }^{2}$ Department of Civil Engineering, Kangwon National University, 24341 Chuncheon, Republic of Korea \\ Correspondence should be addressed to Nam-Hyoung Lim; nhrim@cnu.ac.kr
}

Received 23 August 2017; Accepted 12 November 2017; Published 14 January 2018

Academic Editor: Chiara Bedon

Copyright $(92018$ Hyun-Ung Bae et al. This is an open access article distributed under the Creative Commons Attribution License, which permits unrestricted use, distribution, and reproduction in any medium, provided the original work is properly cited.

Fatal train accidents usually involve derailments or collisions. These derailment/collision accidents are infrequent. However, the damage due to derailment can be catastrophic. Derailment containment walls are usually used in Korea to minimize such damages. However, the impact forces that are needed to design the derailment containment walls were not well defined, and only limited studies were conducted for the behavior of the derailment containment walls. In this study, the focus was made on the impact force analysis of the containment wall through a series of 3D collision simulation after train derailment. Finite element modeling was conducted to analyze the dynamic behavior of the derailed train that collides with a structure such as containment wall using the LS-DYNA analysis software application. The FE models of car bodies, bogie frames, and wheel sets were created such that full conformity was achieved between their numerical models and actual vehicles with respect to the masses and principal mass moments of inertia. In addition, various installation situations of the containment wall were considered for the collision simulation. Finally, the economical alternative method to reduce the impact force was proposed.

\section{Introduction}

Fatal train accidents are usually caused by derailments or collisions. These derailment/collision accidents are infrequent. However, when they occur, the damage is catastrophic. Therefore, protection infrastructure is installed to minimize such damage. In principle, the most ideal preparation is to prevent derailments from occurring. However, it is also necessary to consider the physical means needed to reduce/minimize damage by unexpected accidents such as natural disasters or man-made hazards. This is a concept of protection for derailed trains $[1,2]$.

There are representative accidents that would occur if a derailed train collided with an overbridge or a surrounding building or two trains crashed into each other and then fell under a bridge substructure [2]. The main factors are the spread and amplification of secondary damage by the behavior after the derailments (primary damage). In other words, if secondary collisions with surrounding buildings by a derailed train are prevented, the damage would be mitigated or minimized. In addition, if the secondary derailment resulting from a collision between trains or falling under a bridge is prevented, the damage would be significantly reduced or minimized $[1,2]$.

Since the high-speed railway was induced in Korea, "derailment containment walls" have been constructed to mitigate and minimize accident damage by preventing trains from colliding with catenary poles or falling under a bridge when they are derailed by earthquake, buckling, or defects in tracks/trains in bridge sections. At present, the derailment containment walls are uniformly designed and constructed on bridges serving train speeds of $200 \mathrm{~km} / \mathrm{h}$ or higher. Accordingly, the need for judgment of effectiveness and feasibility review in terms of economics and constructability has been presented by designers and constructors.

The research related to the collision between the derailed train and the protection infrastructure is tenuous in the world. In the previous research [2], we developed the 3D collision simulation model after train derailment. In this paper, using this collision simulation model, various 


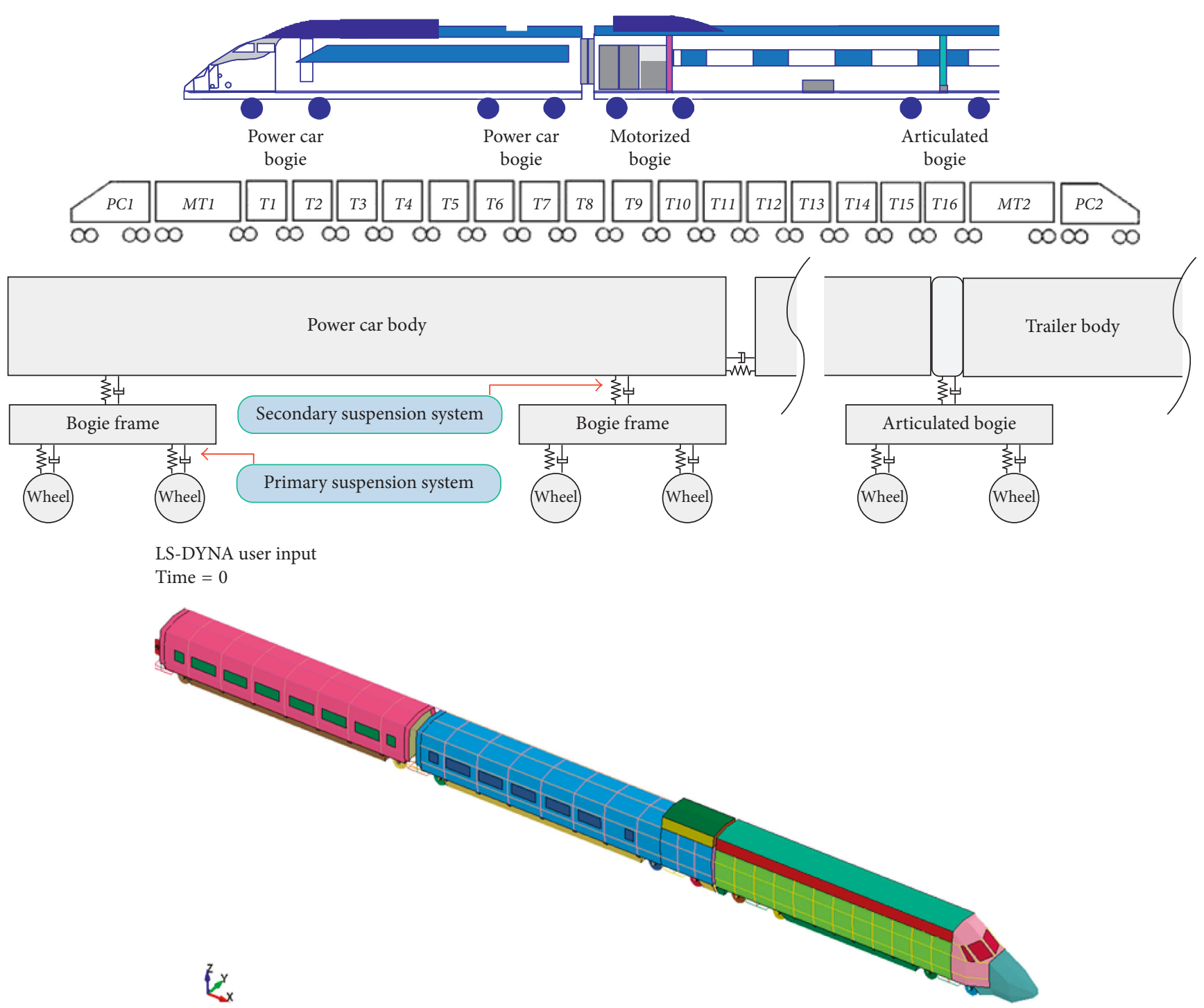

Figure 1: Model concept of KTX.

installation situations of the containment wall were considered by the parameters (location and height of the wall) that affect the impact force and containment effects of the containment walls. Therefore, we propose the advantageous geometric condition of the containment wall through the collision simulation (between the derailed train and the protection infrastructure) after train derailment. Finally, the economical alternative method to reduce the impact force was proposed.

\section{Analysis Model}

FE modeling was conducted to analyze the dynamic behavior of the three-dimensional train and structure using the LS-DYNA [3] nonlinear finite element analysis software application (Version 971). This analysis model developed in the preceding research [2] was verified by several methods. For the numerical verification about energy balance before and after collision of the train, simulations were performed for a collision accident scenario (i.e., a head-on collision accident scenario) of the railroad cars defined by Railroad Safety Act [4]. In addition, it was confirmed that the typical derailment behavior (slip and rollover) of the train model was reproduced correctly through comparison with the theoretical wheelset derailment model by the preceding researchers [5, 6]. Moreover, the analysis model collision behavior when a derailed train collides with a structure such as containment wall was verified by results of the previous research [7].

The train model is a Korea Train eXpress (KTX) highspeed train, operated by Korean railways as shown in Figure 1. The rail was modeled by the head profile of UIC 60 Rail, and the standard gauge of a track was applied with a width of $1,435 \mathrm{~mm}$ as shown in Figure 2. The track types were modeled by a concrete slab. Table 1 shows the element used in LS-DYNA for modeling the track.

Contact conditions between the train and track were modeled using 3D contact elements such as surface-tosurface and node-to-surface as shown in Figure 3 and Table 2. The values of friction coefficient are based on 


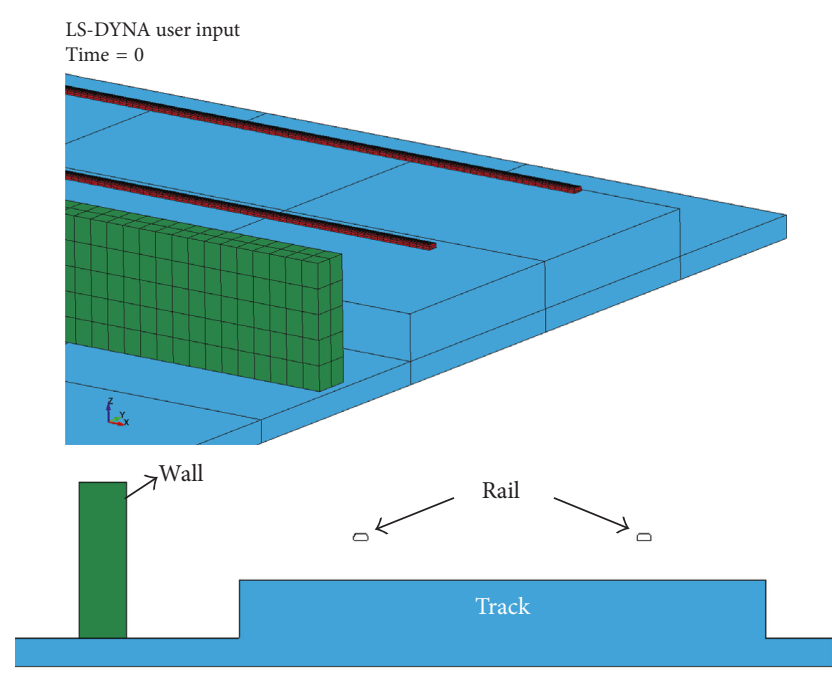

FIgURE 2: Modeling of the track.

TABLE 1: The element used in LS-DYNA for modeling the track.

\begin{tabular}{lc}
\hline Component & Element used in LS-DYNA \\
\hline Rail (UIC 60/gauge & *SECTION_SHELL/*MAT_RIGID \\
$1,435 \mathrm{~mm})$ & *SECTION_SOLID/*MAT_ELASTIC \\
Track and wall (concrete) & (i)Young's modulus: $31,000 \mathrm{MPa}$ \\
& (ii)Poisson's ratio: 0.2 \\
\hline
\end{tabular}
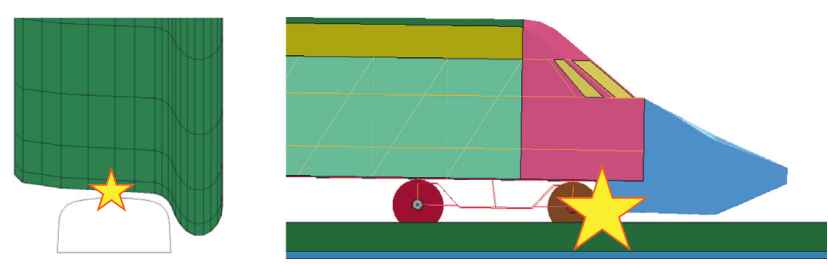

Figure 3: Contact conditions between the train and track.

TABle 2: Contact conditions between the train and track.

\begin{tabular}{lc}
\hline Contact condition & Friction coefficient \\
\hline Wheel $\sim$ rail $($ general surface) & $F_{\text {stat. }}=0.4 / F_{\text {dyn. }}=0.3$ \\
Wheel $\sim$ concrete slab (surface to surface) & $F_{\text {stat. }}=0.55 / F_{\text {dyn. }}=0.45$ \\
$\begin{array}{l}\text { Train } \sim \text { wall }(\text { surface to surface } \\
\text { and nodes to surface) }\end{array}$ & $F_{\text {stat. }}=0.0 / F_{\text {dyn. }}=0.0$ \\
\hline
\end{tabular}

references [8, 9]. However, in reality, measuring and identifying the frictional force between the train and the wall when collision is very difficult because it is occurred by the impact for a split second (it is supposedly close to zero). In Moyer's study conducted in the U.S. [10], the effect on impact force with respect to increase of magnitude of frictional force was investigated- "This parameter has very little effect, although higher barrier friction increases impact forces slightly." Therefore, the friction coefficients between the train and the wall were ignored in this study.

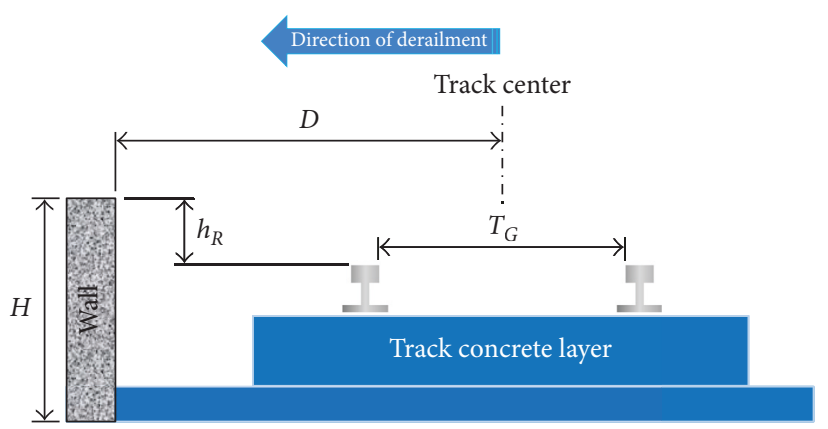

FIgURE 4: Geometric conditions of the containment wall on the railway bridge in Korea.

TABLE 3: Geometric condition of the track.

\begin{tabular}{lcccc}
\hline Line & $H(\mathrm{~mm})$ & $h_{R}(\mathrm{~mm})$ & $T_{G}(\mathrm{~mm})$ & $D(\mathrm{~mm})$ \\
\hline Gyeongbu HSR & 975 & 271 & 1,435 & $2,000\left(1.39 T_{G}\right)$ \\
Honam HSR & 940 & 234 & 1,435 & $1,880\left(1.31 T_{G}\right)$ \\
\hline
\end{tabular}

Table 4: Analysis cases.

\begin{tabular}{|c|c|c|c|c|}
\hline Parameter & Case & $D$ & $\begin{array}{c}h_{R} \\
(\mathrm{~mm})\end{array}$ & Remark \\
\hline \multirow{4}{*}{ Effect of $D$} & Case 1 & $0.98 T_{G}$ & 271 & $\begin{array}{c}\text { Decrease } D \text { based } \\
\text { on Case } 3\end{array}$ \\
\hline & Case 2 & $1.31 T_{G}$ & 234 & $\begin{array}{c}\text { Honam HSR reference } \\
\text { model }\end{array}$ \\
\hline & Case 3 & $1.39 T_{G}$ & 271 & $\begin{array}{l}\text { Gyeongbu HSR } \\
\text { reference model }\end{array}$ \\
\hline & Case 4 & $1.60-1.90 T_{G}$ & - & $\begin{array}{l}\text { Guidance by } \\
\text { running rail }\end{array}$ \\
\hline \multirow{3}{*}{ Effect of $h_{R}$} & Case 5 & $1.39 T_{G}$ & 436 & $\begin{array}{c}\text { Increase } h_{R} \text { based } \\
\text { on Case } 3\end{array}$ \\
\hline & Case 6 & $0.98 T_{G}$ & 436 & $\begin{array}{c}\text { Increase } h_{R} \text { based } \\
\text { on Case } 1\end{array}$ \\
\hline & Case 7 & $0.98 T_{G}$ & 106 & $\begin{array}{c}\text { Decrease } h_{R} \text { based } \\
\text { on Case } 1\end{array}$ \\
\hline
\end{tabular}

\section{Parametric Study to Evaluate the Effects of the Containment Wall}

The parameters affecting the impact force and containment effects of the containment walls were selected as the location and height of the wall. The geometric conditions and material properties of the track were modeled based on the conditions of the Gyeongbu High-Speed Railway and Honam High-Speed Railway (concrete track) in Korea as shown in Figure 4 and Table 3. The details of analysis cases are shown in Table 4. The simulation train speed is $300 \mathrm{~km} / \mathrm{h}$.

Unless considering the rail to be the train derailment condition, the train is supposed as the already derailed train and only expected incident angle and speed are analyzed as variables. Therefore, the behavior after derailment becomes consistent. This study reproduced the drop of wheels from the rail to reproduce the actual derailment as closely as 


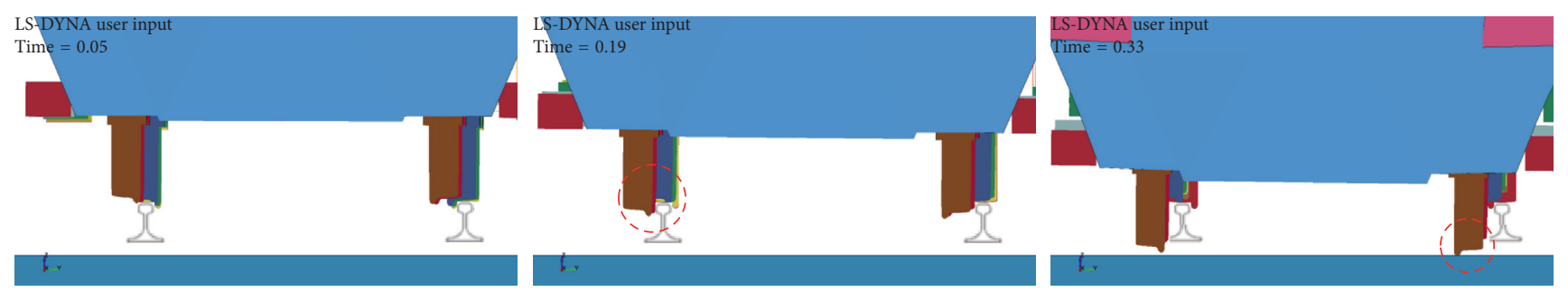

FIgURE 5: Derailment behavior by wheel climbing on simulation.

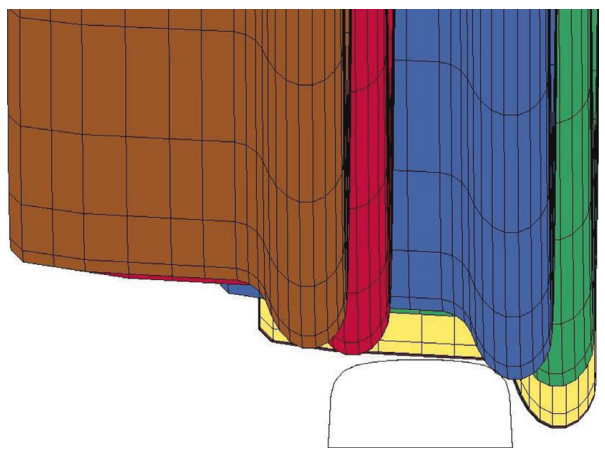

Figure 6: Derailment situation of wheels by wheel climbing on simulation.

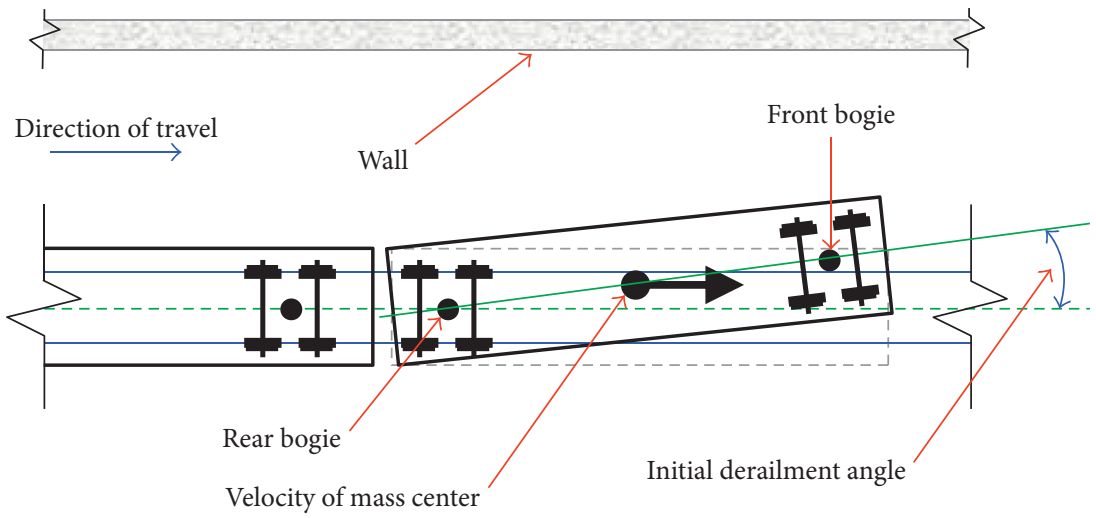

Figure 7: Initial derailment angle on simulation.

possible. Therefore, many changes were effected in the train behavior after derailment as the falling points of wheels were changed by the interference of the wheels and rails (Figure 5). The derailment behavior was reproduced under the slip and rollover condition by wheel climbing (Figure 6).

As soon as wheels of the front and rear bogie drop from the rail head, the car veer off to the wall and rotates about the vertical axis of the rear bogie as shown in Figure 7. At this time, angle between the longitudinal axis of the car and the track center is called "derailment angle" as shown in Figure 7. A certain initial value of the derailment angle was assumed for the convenience of the analysis. Initial derailment angles from 0.3 to $0.4^{\circ}$ were supposed considering a rail surface. (If the initial derailment angle is less than $0.3^{\circ}$, the derailment does not occur well by wheel flange. Also, if the angle is greater than $0.4^{\circ}$, it will fall directly onto the track surface without the interference of the wheels and rails.) The initial velocity vertor $(300 \mathrm{~km} / \mathrm{h})$ of the mass center of the first car remains parallel to the track centerline.

\subsection{The Effect of Separation Distance from Track Center}

3.1.1. $D=1,400 \mathrm{~mm}\left(0.98 \mathrm{~T}_{G}\right)$. Case 1 (distance effect 1 ) has minimized the separation distance $(D)$ of the containment wall from the track center by putting the wall closer to the track concrete layer (TCL), as shown in Figure 8. In the case of derailment-collision behavior 1 as shown in Figure 9(a), the axlebox collides with the containment wall after the drop of the wheels on the concrete surface (TCL). Then, the first impact force is $160 \mathrm{kN}$, but the subsequent impact forces increase due to repetitive impact of the axleboxes between the rail and the wall. In the case of derailment-collision behavior 2 as shown in Figure 9(b), the axlebox collides with the containment wall before the drop of the wheels on the 


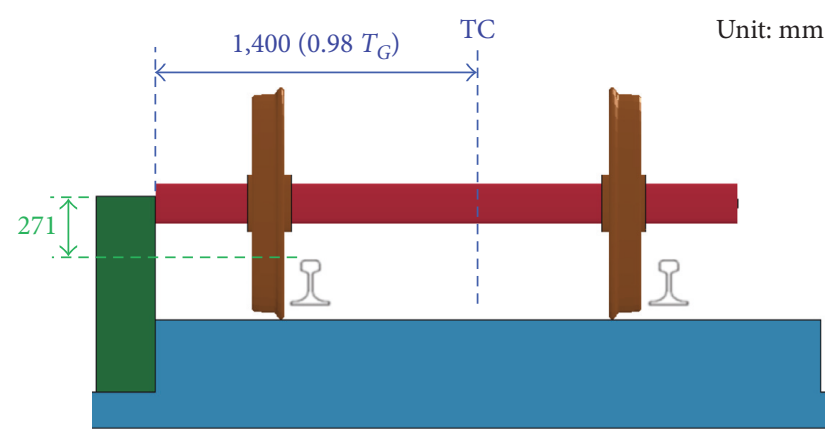

Figure 8: Overview of distance effect 1.
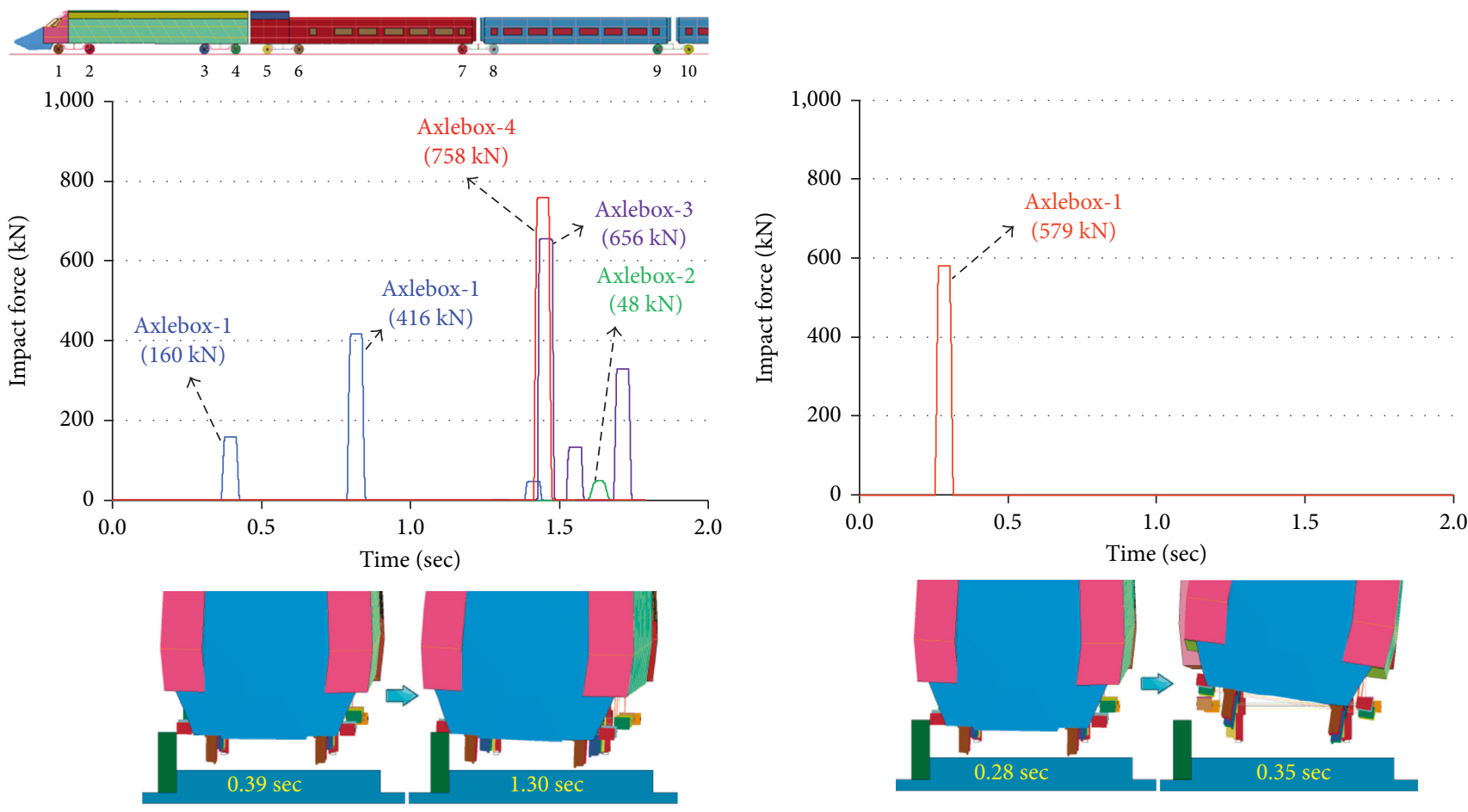

(a)

(b)

Figure 9: Derailment-collision behavior and impact force (distance effect 1). (a) Derailment-collision behavior 1. (b) Derailment-collision behavior 2 .

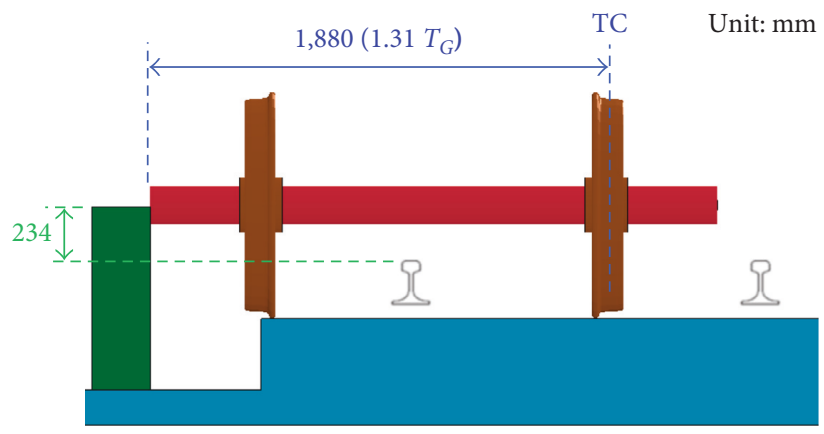

Figure 10: Overview of distance effect 2. 

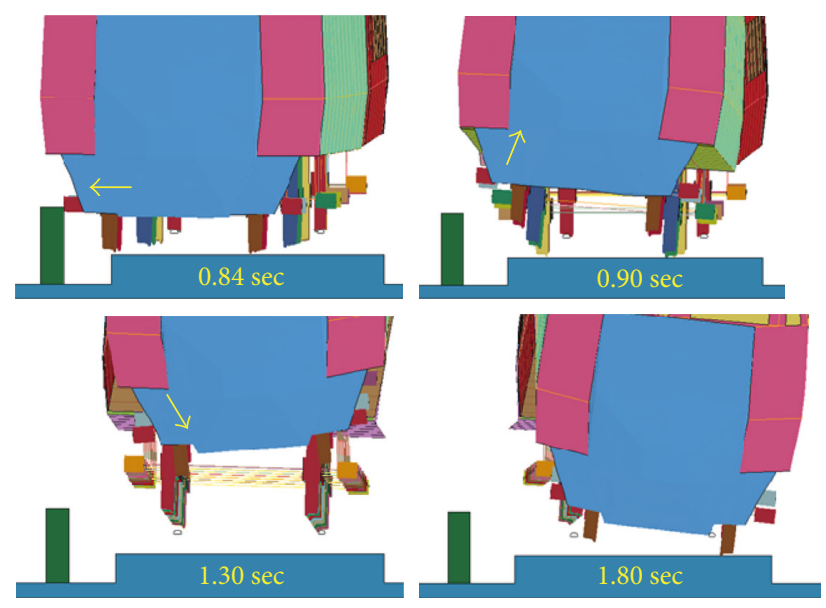

< Impact force: $1,548 \sim 3,619 \mathrm{kN}>$

FIGURE 11: Derailment-collision behavior and impact force (distance effect 2).

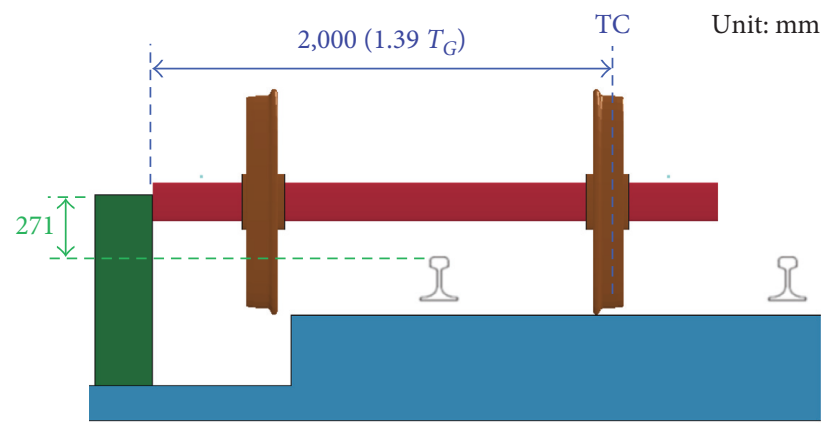

FIGURE 12: Overview of distance effect 3.

concrete surface. Then, the impact force is computed at $579 \mathrm{kN}$, and the derailed train bounces to the inner track. In both behaviors, if the containment wall is not destroyed by collision, the horizontal deviation of a derailed train is contained within the intended area (track area) after collision.

3.1.2. $D=1,880 \mathrm{~mm}\left(1.31 \mathrm{~T}_{G}\right)$. In Case 2 of distance effect 2 , the separation distance $(D)$ of the containment wall from the track center is set from $1.0 T_{G}$ to $1.5 T_{G}$ : the condition of Honam HSR (Figure 10). In this case, the impact force is significantly greater than distance effect 1 . In this case, the impact force acting on the containment wall is computed as a range of about 1,500 to $3,900 \mathrm{kN}$ in accordance with collision conditions that considerably vary due to derailment conditions (interference of the wheels and rails). As shown in Figure 11, if the containment wall is not destroyed by collision, the horizontal deviation of a derailed train is contained within the intended area (track area) after collision.

3.1.3. $D=2,000 \mathrm{~mm}\left(1.39 T_{G}\right)$. In Case 3 of distance effect 3 , the separation distance $(D)$ of the containment wall from the track center is set from $1.0 T_{G}$ to $1.5 T_{G}$ : the condition of
Gyeongbu HSR (Figure 12). In this case, the impact force is also greater than distance effect 1 , like distance effect 2 . In this case, the impact force acting on the containment wall is computed for the range of about 600 to $4,000 \mathrm{kN}$ in accordance with collision conditions. As shown in Figure 13, if the containment wall is not destroyed by collision, the horizontal deviation of a derailed train is contained within the intended area (track area) after collision.

3.1.4. $D=$ More than 2,300 $\mathrm{mm}\left(1.60-1.90 T_{G}\right)$. Case 4 (distance effect 4) has sufficiently extended the separation distance $(D)$ until the inner wheels of a derailed train can be guided by running a rail before the outer (derailment direction) wheels collide with the containment wall (Figure 14).

The concept of this case is based on derailment containment concepts in the UK $[11,12]$ and Germany [13] that the primary impact damage be restricted by a running rail, and then the wall secondarily contains the horizontal deviation to a reduced force. Hence, the horizontal impact forces of the containment wall can be advantageous in terms of containment wall design.

The separation distance $(D)$ from the track center must be more than $1.60 T_{G}$ in order that a wheel does not contact the containment wall and more than $1.88 T_{G}$ in order that an 


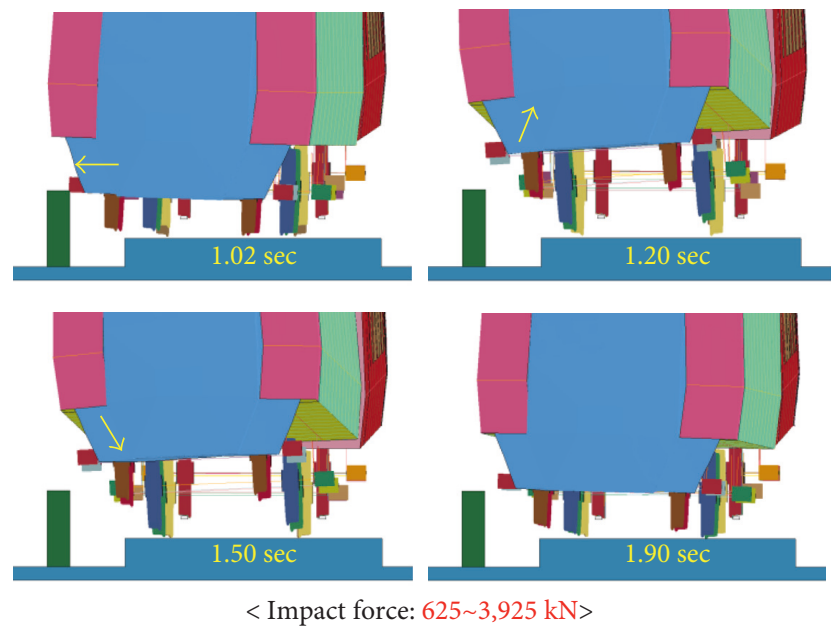

FiguRe 13: Derailment-collision behavior and impact force (distance effect 3).

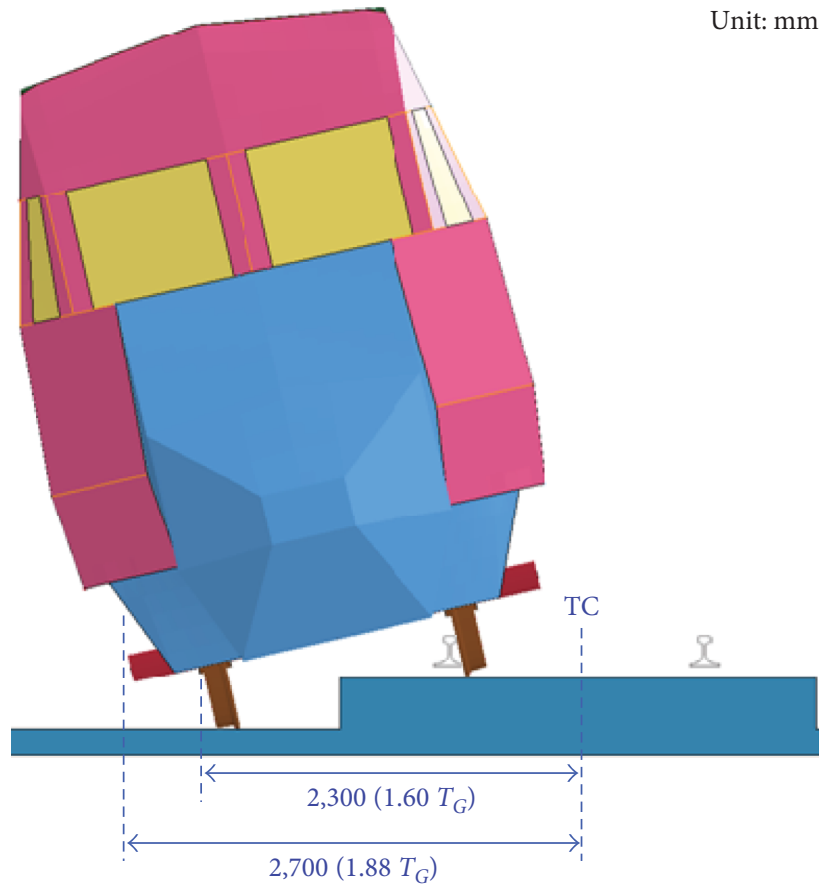

Figure 14: Overview of distance effect 4.

axlebox does not contact the containment wall (Figure 14). The dimensions of the wheel and the axlebox are that of the KTX train, and the track gauge $\left(T_{G}\right)$ is $1,435 \mathrm{~mm}$ (standard gauge).

In the case of derailment-collision behavior 1 as shown in Figure 15(a), the first wheel vertically jumps after colliding with the rail, and then the 5th and 6th wheels of succeeding trailers (motorized bogie) also are sequentially guided by the rail. In case of derailment-collision behavior 2 as shown in Figure 15(b), the first wheel is vertically jumped from the ground due to severe snap behavior without contact with the rail. Hence, a derailed train has the possibility of collision with catenary ducts/poles, or falling under a bridge because of the impossibility of containment protection by the running rail. Therefore, a containment wall of the outer side structure type is needed in this case. Also, this case shows that perfectly protecting the derailed train for all the derailment situations/conditions is impossible.

\subsection{The Effect of Height above Rail Surface}

3.2.1. $h_{R}=436 \mathrm{~mm} / \mathrm{D}=2,000 \mathrm{~mm}\left(1.39 T_{G}\right)$. Case 5 (height effect 1) has extended the height of the containment wall $\left(h_{R}\right)$ until the whole area of the axlebox can contact the containment wall (Figure 16). In this case, the collision behavior has consistency, without varying collision behaviors (the gap of impact force due to deference of contact area) according to the derailment conditions. And the containment effect of 


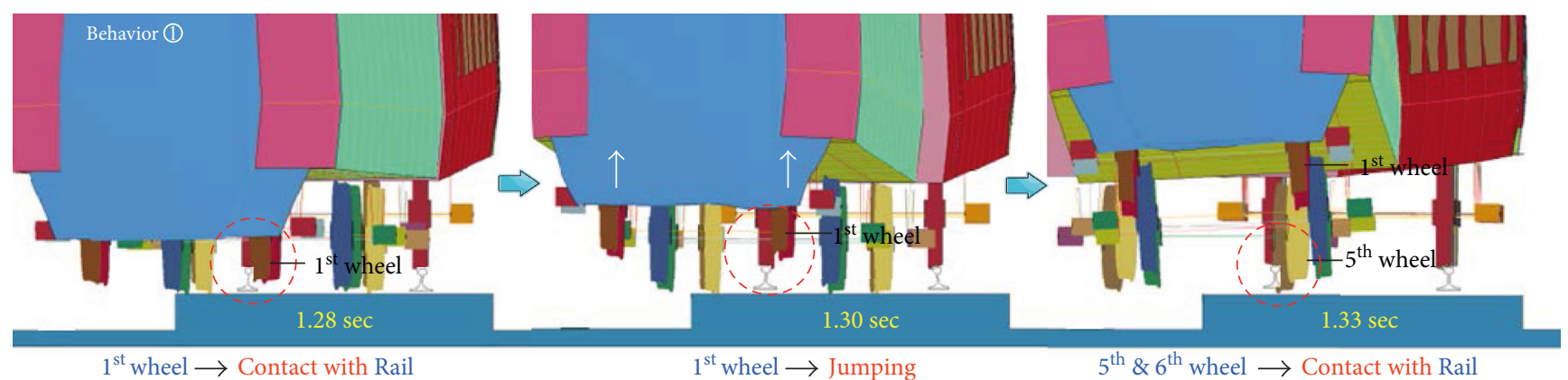

(a)

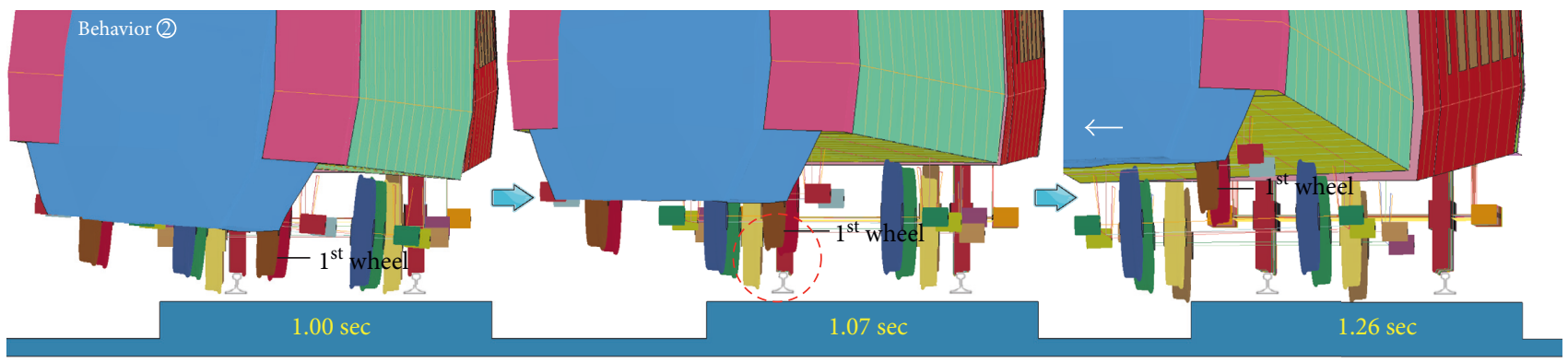

$1^{\text {st }}$ wheel $\rightarrow$ No contact with Rail

(b)

FIgURE 15: Derailment-collision behavior (distance effect 4). (a) Behavior 1. (b) Behavior 2.

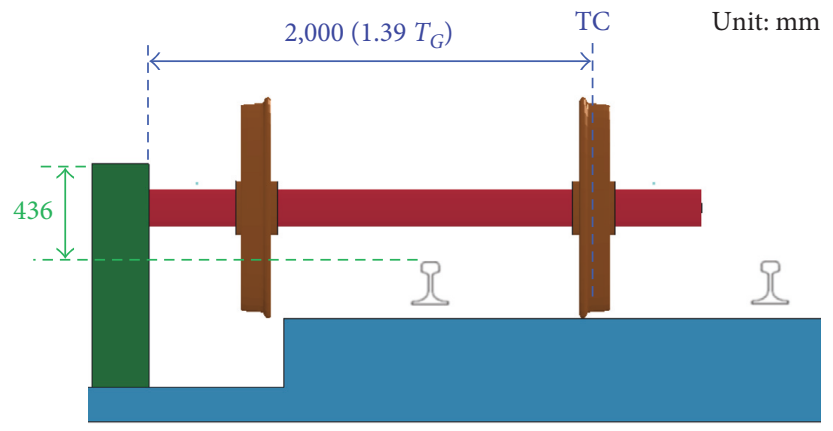

Figure 16: Overview of height effect 1.

a derailed train is excellent as shown in Figure 17. However, the maximum impact force acting on the containment wall is the greatest: $4,064 \mathrm{kN}$.

3.2.2. $h_{R}=436 \mathrm{~mm} / \mathrm{D}=1,400 \mathrm{~mm}\left(0.98 \mathrm{~T}_{\mathrm{G}}\right)$. Case 6 (height effect 2) has minimized the separation distance $(D)$ of the containment wall from the track center by putting the wall closer to the TCL and has extended the height of the containment wall $\left(h_{R}\right)$ until the whole area of the axlebox can contact the containment wall (Figure 18). In this case, the collision behavior has consistency without varying collision behaviors according to the derailment conditions. And the containment effect of a derailed train is excellent as shown in Figure 19. Also, the impact force $(1,168 \mathrm{kN})$ is considerably smaller than the height effect $1(4,064 \mathrm{kN})$ because of reduction of inertial force due to reduced lateral behavior distance of the derailed train. However, the subsequent impact forces are likely to increase due to repetitive impact of the axlebox between the rail and the wall.

3.2.3. $h_{R}=106 \mathrm{~mm} / \mathrm{D}=1,400 \mathrm{~mm}\left(0.98 \mathrm{~T}_{G}\right)$. Case 7 (height effect 3) minimizes the separation distance $(D)$ of the containment wall from the track center by putting the wall closer to the TCL and has reduced the height of the containment wall $\left(h_{R}\right)$ until the axlebox does not collide with the containment wall, but the wheel can contact the containment wall (Figure 20). In this case, the impact force $(500$ to $850 \mathrm{kN})$ is much smaller than in the height effect 1 $(4,064 \mathrm{kN})$. In addition, repetitive impact is less likely to 

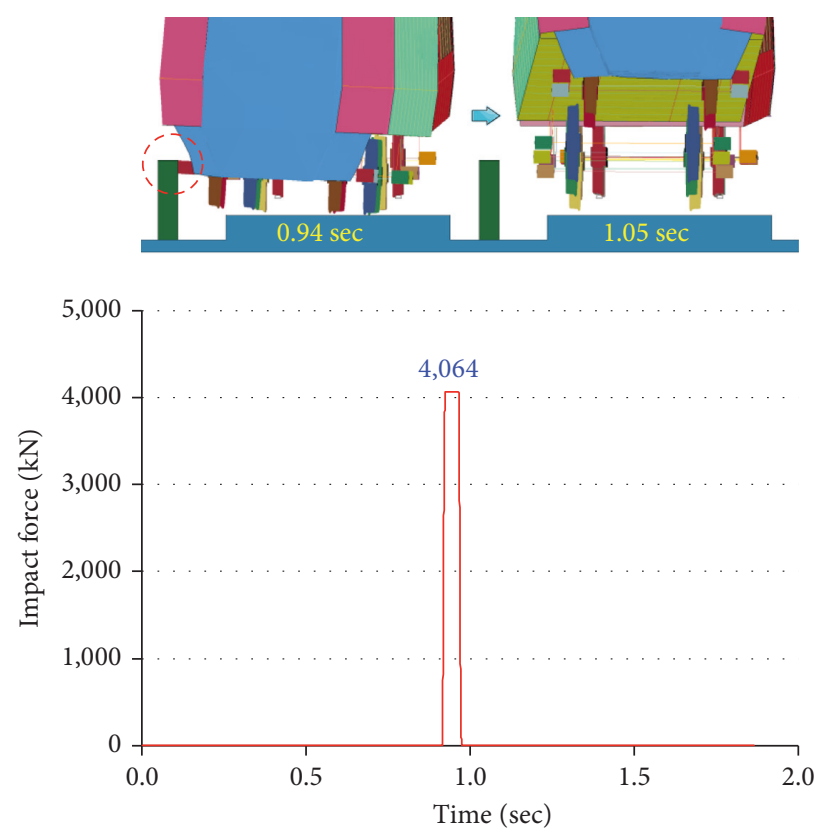

(a)
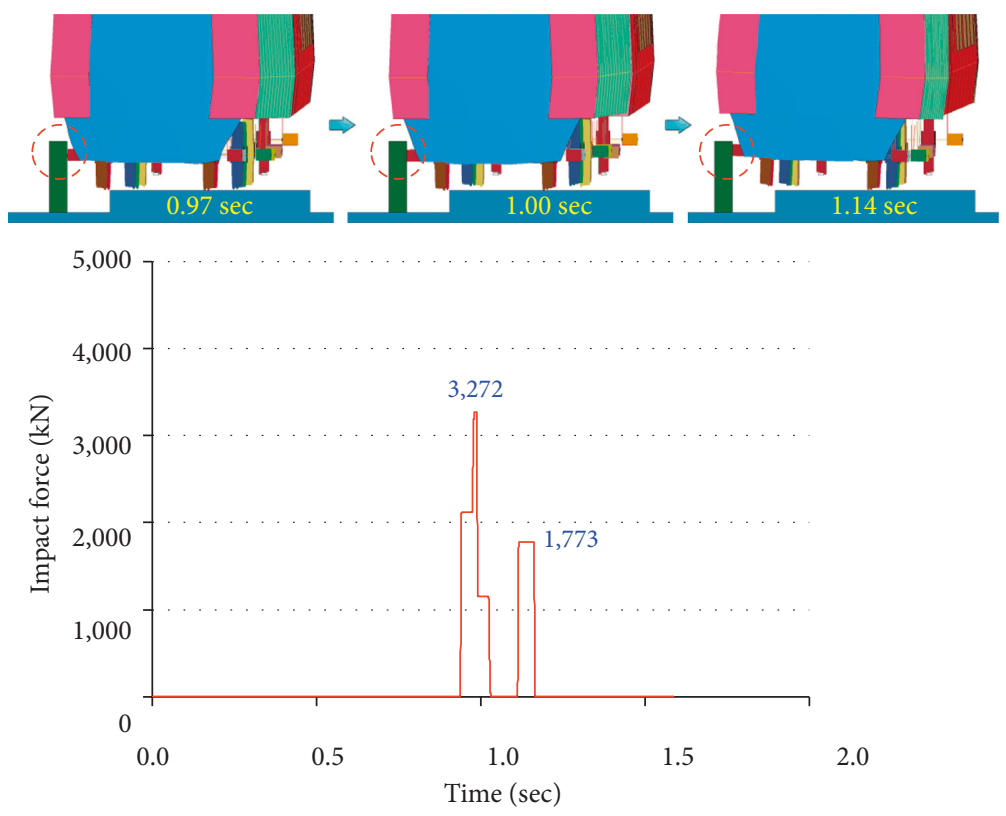

(b)

FIgURE 17: Derailment-collision behavior and impact force (height effect 1). (a) Derailment-collision behavior 1. (b) Derailment-collision behavior 2.

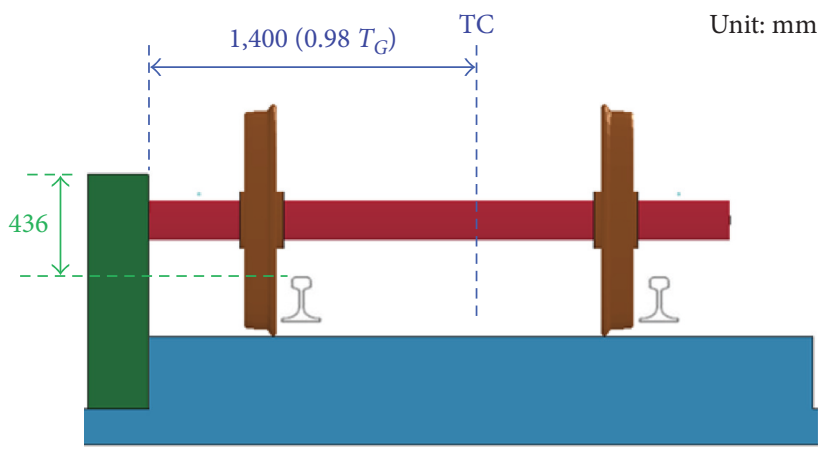

Figure 18: Overview of height effect 2. 

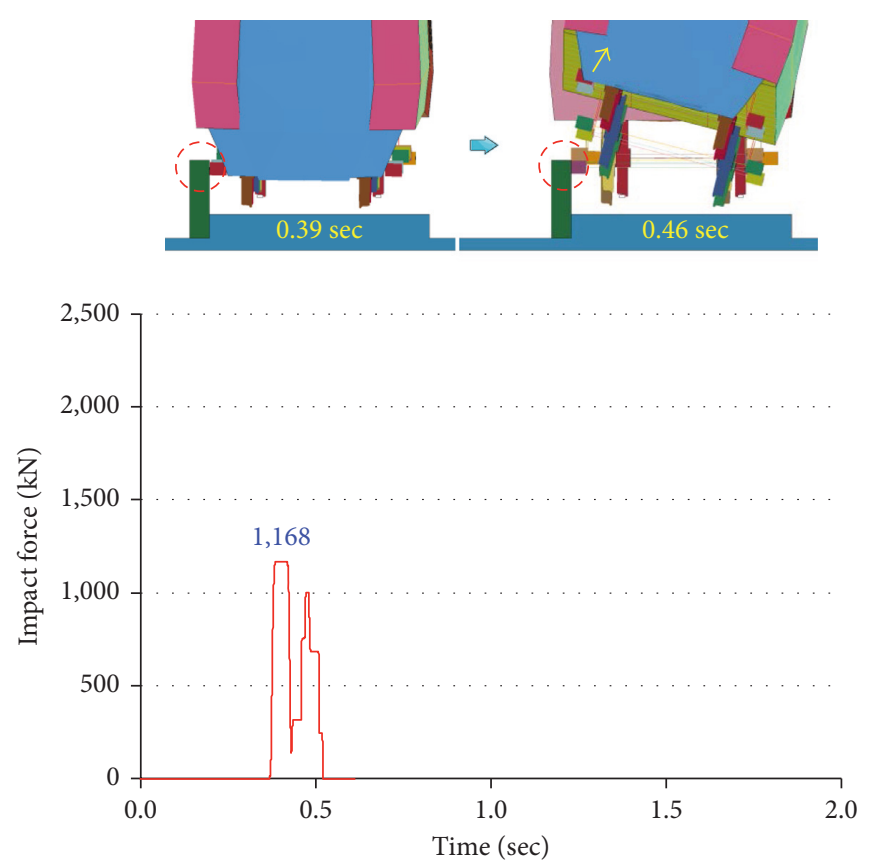

FIgURE 19: Derailment-collision behavior and impact force (height effect 2).

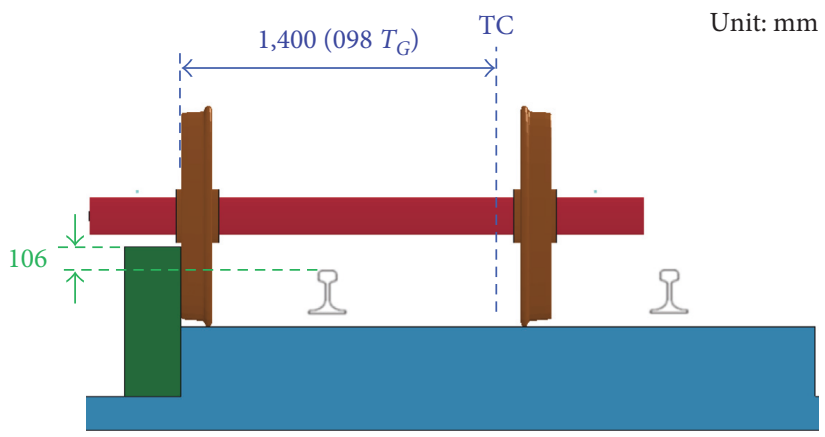

Figure 20: Overview of height effect 3.

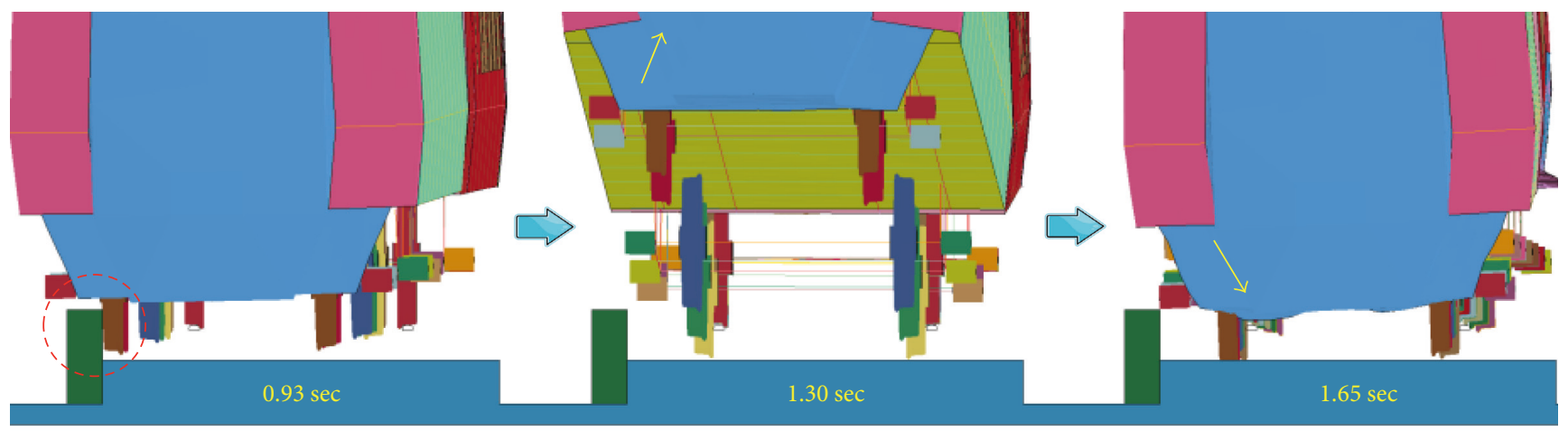

< Impact force: $555 \sim 815 \mathrm{kN}>$

FIgURE 21: Derailment-collision behavior and impact force (height effect 3).

occur between the rail and the wall compared with the height effect 2. As shown in Figures 21 and 22, the collision behaviors due to difference of the contact area can vary according to the derailment conditions, but the impact force $(500$ to $850 \mathrm{kN})$ is smaller than both the height effect 2
$(1,168 \mathrm{kN})$ and the distance effect $1(160$ to $1,500 \mathrm{kN})$. Also, this case has an advantage in economical efficiency since height of the wall is reduced but also has a disadvantage for the difficulty of maintenance work for the inspection of cracks on the TCL side. 

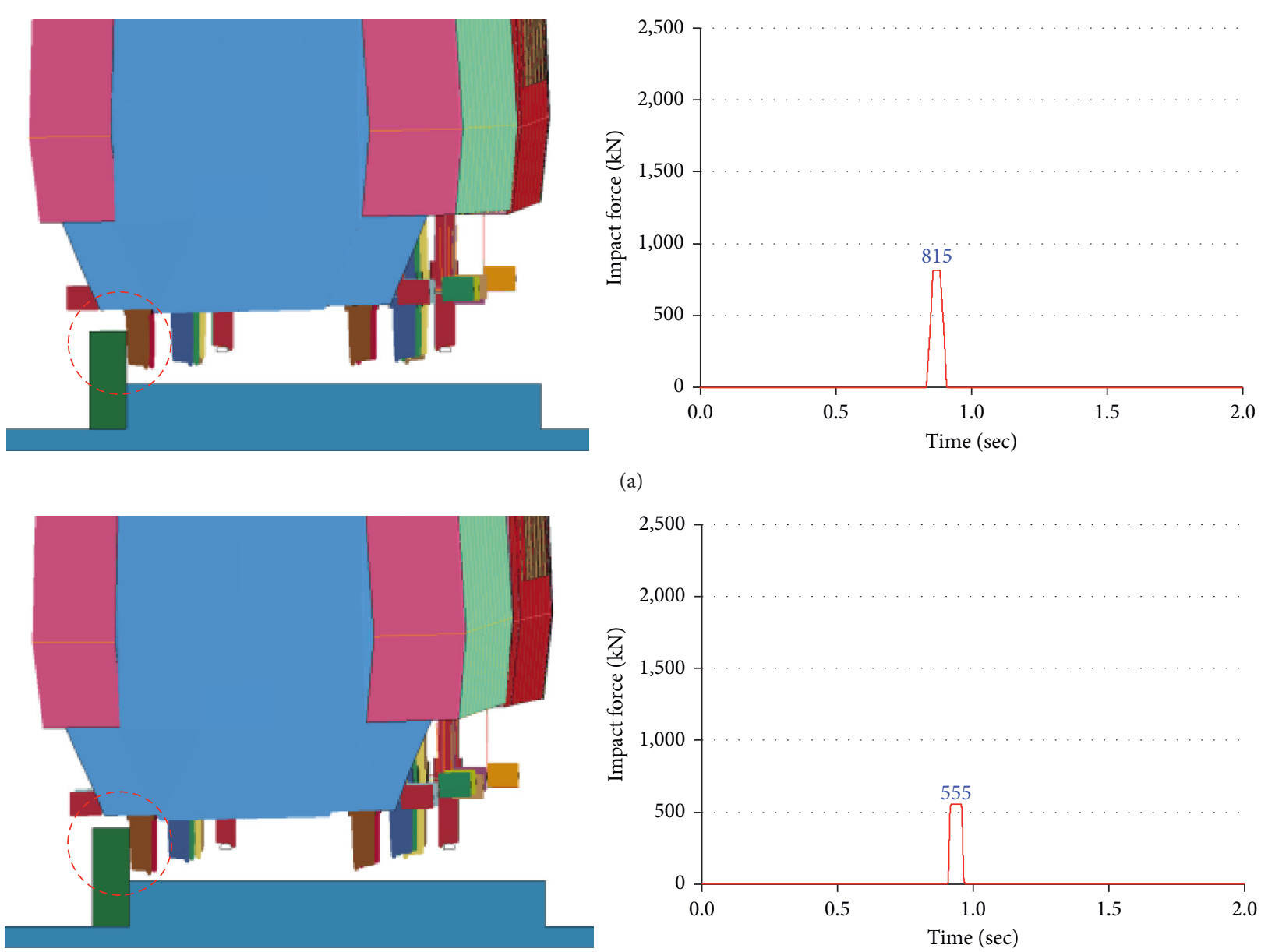

(b)
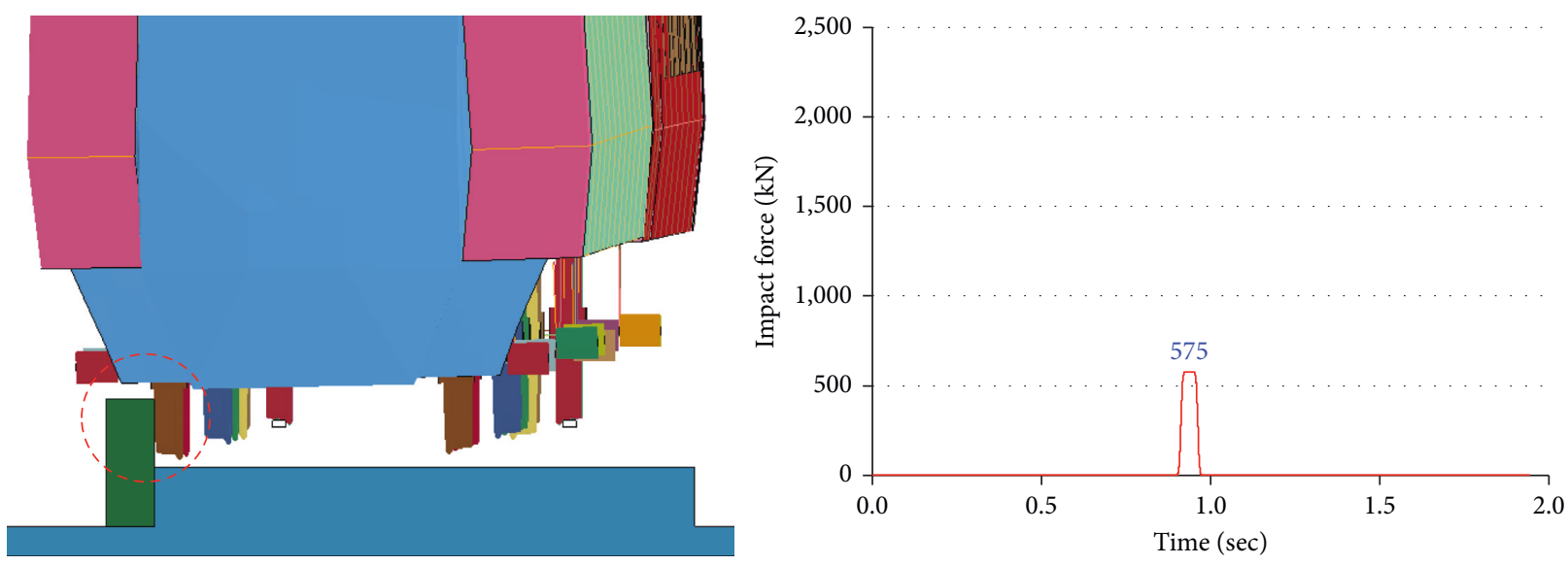

(c)

FIgURE 22: Impact force according to the collision conditions. (a) Derailment-collision behavior 1. (b) Derailment-collision behavior 2. (c) Derailment-collision behavior 3 .

3.3. Alternative Method: Containment Wall within Track Gauge. A concrete track with the containment effect of a derailed train was modeled as shown in Figure 23 on the basis of the HSL-Zuid Project [14] that applies concrete plinth $(500 \times 170 \mathrm{~mm})$ that is a structure type within track gauge. The horizontal deviation of a derailed train can be contained against derailment, both inside and outside of a bridge.
The impact force applied to the containment wall (or block) was computed for a range of about 100 to $250 \mathrm{kN}$ depending on the difference of the contact area between the train and wall in accordance with collision conditions (Figure 24), and the containment effect of a derailed train is sufficient despite the jumping phenomenon. This containment wall (or block) has an advantage in economic and 


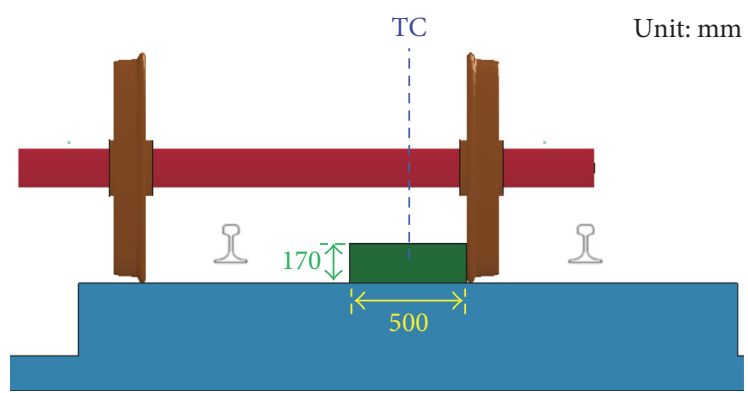

Figure 23: Overview of the containment wall (or block) within track gauge.

durable efficiency due to reduction of impact force (about 93\% at worst case) in comparison with the containment wall (Figure 17), which is the outer side structure type of track. However, in order to apply concrete plinth above the concrete track, a new concrete track should be developed considering the interface to the track, electricity, signal, etc.

3.4. Summary of Analysis Results. This section summarizes the results according to the parametric analysis to evaluate the effects of the containment wall as shown in Table 5.

(1) Separation distance less than track gauge $(D=$ less than $1.0 T_{G}$ )
(a) Collision with the containment wall by small inertia force
(b) Impact forces: $160-1,500 \mathrm{kN}$

(2) Uncertain separation distance more than track gauge $\left(D=1.3-1.4 T_{G}\right)$
(a) Collision with the containment wall by great inertia force
(b) Impact forces: $600-4,000 \mathrm{kN}$

(3) Enough separation distance $\left(D=\right.$ more than $\left.1.6 T_{G}\right)$

(a) The reduced force acts on the containment wall after primary guidance by the running rail

(b) The reasonable force level can be applied as the horizontal design load of the containment wall

As results of the analysis on distance effects, we present the optimum separation distance as follows: (1) separation distance less than track gauge or (2) enough separation distance.

(1) Height greater than the section of the axlebox $\left(h_{R}=\right.$ more than $\left.440 \mathrm{~mm}\right)$

(a) The whole area of the axlebox collides with the containment wall

(b) The containment effect of a derailed train is excellent, but the magnitude of maximum impact force is disadvantageous

(c) Impact forces: $1,000-4,100 \mathrm{kN}$

(2) Height less than section of the axlebox $\left(h_{R}=\right.$ less than $100 \mathrm{~mm}$ )

(a) The wheel collides with the containment wall (b) The containment effect of a derailed train is sufficient, and the magnitude of maximum impact force is advantageous

(c) Impact forces: $500-850 \mathrm{kN}$

As results of the analysis on height and separation distance effects, we present the optimum height and separation distance as follows: (1) separation distance less than track gauge and height less than the axlebox (wheel level) or (2) enough separation distance and height less than the axlebox (wheel level).

(1) Containment wall or block (wheel level) within track gauge

(a) Collision with the containment wall by very small inertia force

(b) Impact forces: $100-300 \mathrm{kN}$

As results of the analysis on the containment wall (or block) within track gauge, we present the alternative condition. This condition has an advantage in economic and durable efficiency due to reduction of impact force in comparison with the outer side wall type.

\section{Conclusions}

In this paper, a collision simulation between the derailed train and structure was carried out to evaluate impact force and containment effect of the containment walls that could be installed to minimize damage to the derailment, and the economical alternative method to reduce the impact force was proposed. The following conclusions were drawn:

(1) As the separation distance of the containment walls is closer to the track center, the behavior range of a derailed train narrows. Therefore, the lateral inertia force decreases, thereby reducing the impact force on the wall. However, the impact force of the containment wall may increase due to repetitive collisions between the wall and the rail.

(2) The containment effect could be assured at low walls where the wheels of the derailed train can collide with walls (not to cause the axlebox to collide with the wall). In addition, this case has an advantage in economical efficiency since height of the wall is reduced but also has a disadvantage for the difficulty 

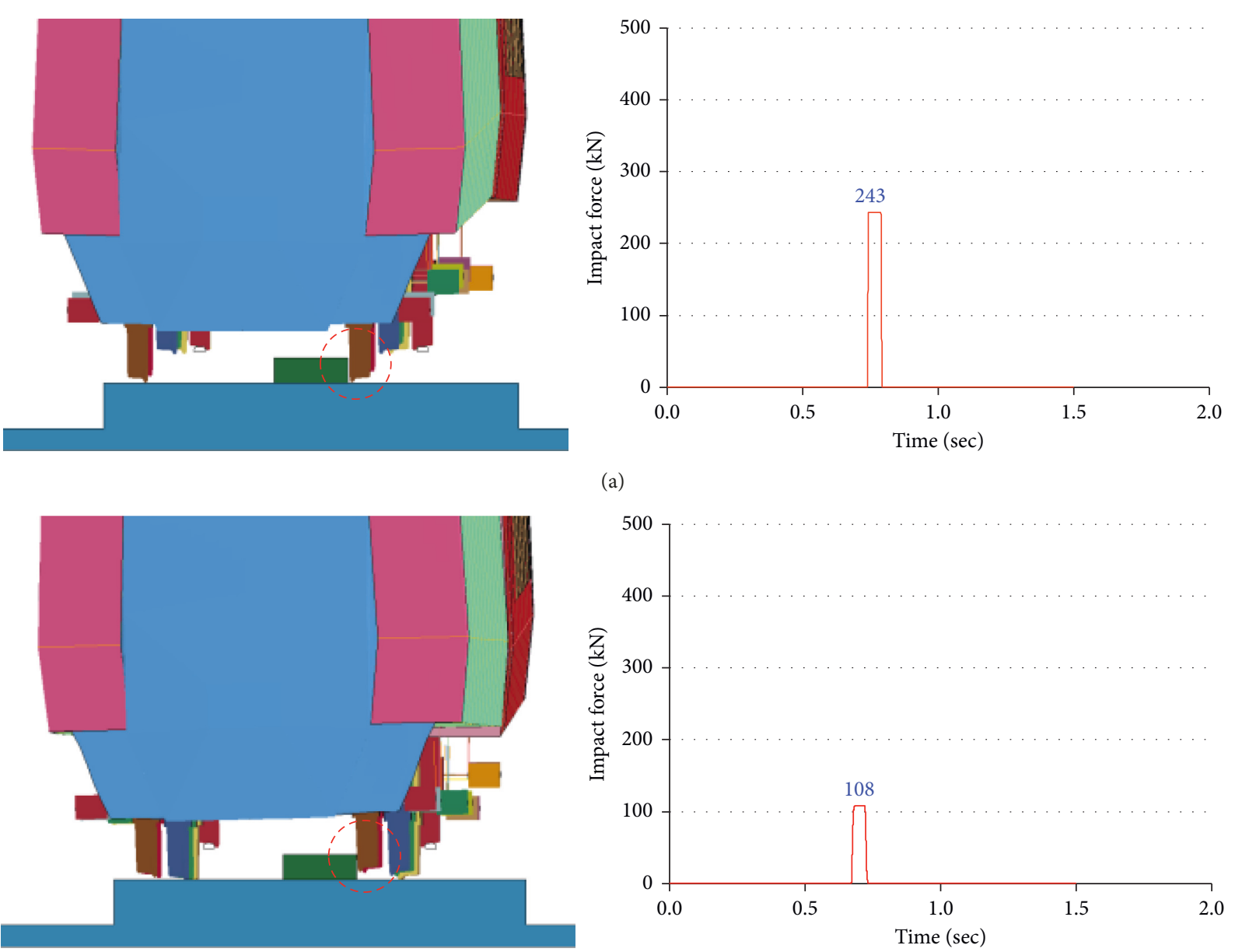

(b)
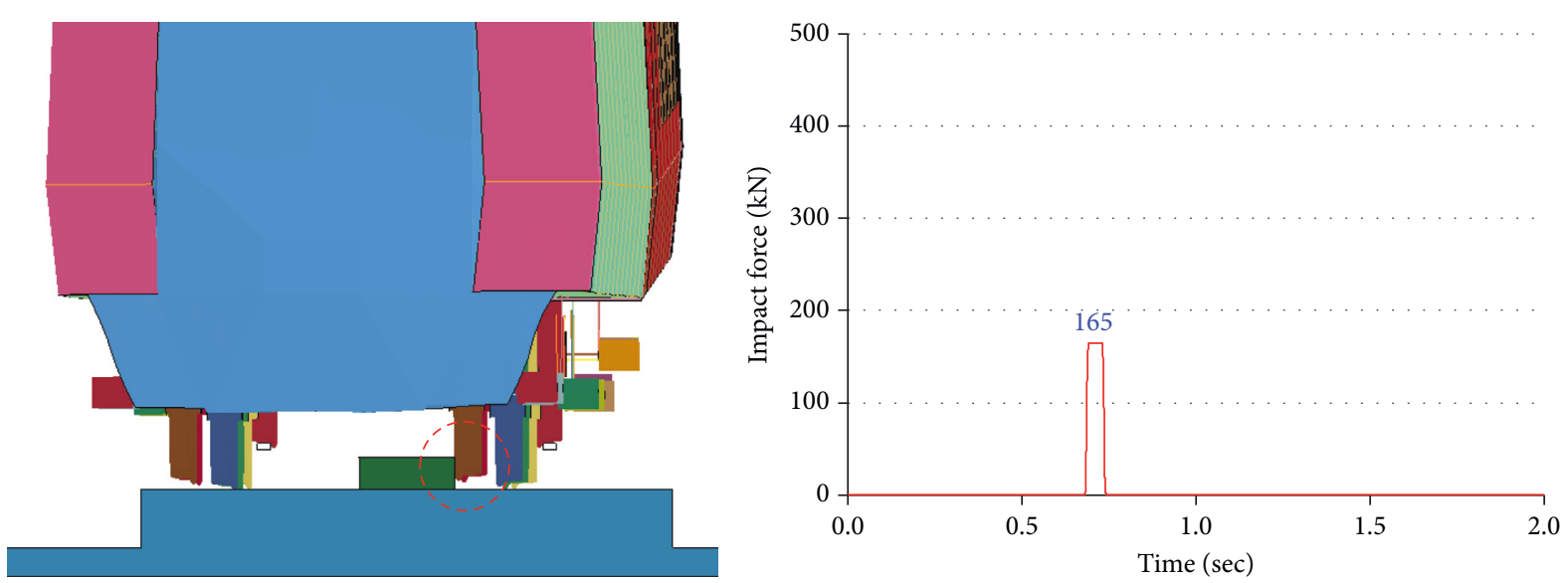

(c)

FIGURE 24: Derailment-collision behavior and impact force (alternative method). (a) Derailment-collision behavior 1. (b) Derailmentcollision behavior 2. (c) Derailment-collision behavior 3 .

of maintenance work for the inspection of cracks on the track concrete layer side.

(3) The containment wall (or block) within track gauge has an advantage in economic and durable efficiency due to reduction of lateral impact force in comparison with the containment wall which is the outer side structure type of track. Moreover, the horizontal deviation of a derailed train can be contained against derailment, both inside and outside of a bridge.

(4) To ensure the containment effect (the derailed trains are placed within intended containment area), the derailment containment wall need to be robustly constructed to resist the impact force due to the 
TABLE 5: Summary for the effects of the containment wall.

\begin{tabular}{lccc}
\hline Parameter & Case & Impact force $(\mathrm{kN})$ & Remark \\
\hline \multirow{3}{*}{ Effect of $D$} & Case 1 & $160-1,500$ & Reducing distance effect \\
& Case 2 and 3 & $600-4,000$ & Uncertain distance \\
& Case 4 & Reduced value & Guided effect by running rail \\
Effect of $h_{R}$ & Case 5 & $3,200-4,100$ & Increasing height/uncertain distance \\
& Case 6 & 1,168 & Increasing height/reducing distance \\
Alternative method & Case 7 & $500-850$ & Reducing height and distance \\
\hline
\end{tabular}

possibility that the succeeding trailers of the derailed train continuously collide to the wall.

\section{Conflicts of Interest}

The authors declare that there are no conflicts of interest.

\section{Acknowledgments}

This research was supported by a grant (17RTRP-B122273-02) from Railway Technology Research Program funded by Ministry of Land, Infrastructure and Transport of the Korean government.

\section{References}

[1] H. U. Bae, Advanced design concept of derailment containment provisions using collision simulation after train derailment [Ph.D. Thesis], Department of Civil Engineering, The Graduate School of Chungnam National University, Republic of Korea, 2015.

[2] H. U. Bae, K. M. Yun, and N. H. Lim, "Containment capacity and crashworthiness estimation of derailment containment wall on high-speed train," Proceedings of the Institution of Mechanical Engineers, Part F: Journal of Rail and Rapid Transit, 2016.

[3] Livermore Software Technology Corporation (LSTC), LS-DYNA Keyword User's Manual, vol. 1-3, Revision 2645, Livermore Software Technology Corporation, CA, USA, 2013.

[4] J. S. Koo, H. J. Cho, and T. S. Kwon, "A study on establishing the accident scenarios for crashworthiness of rolling stocks," in Proceedings of the Spring Conference of the Korean Society for Railway, pp. 1-10, Korean Society for Railway, Jeju, Republic of Korea, May 2007, in Korean.

[5] H. J. Cho, Study on wheel-rail models for prediction of derailment behavior after collision using virtual testing model [Ph.D. Thesis], A Dissertation for the Degree of Doctor of Engineering, Department of Rolling Stock System, The Graduate School of Railroad, Seoul National University of Technology, Republic of Korea, 2010.

[6] J. S. Koo and H. J. Cho, "A method to predict the derailment of rolling stock due to collision using a theoretical wheelset derailment model," Multibody System Dynamics, vol. 27, no. 4, pp. 403-422, 2012.

[7] J. Fukazawa and Y. Sonoda, "Study on the crashworthiness estimation of the derailment barrier," Journal of Applied Mechanics, vol. 11, pp. 459-466, 2008, in Japanese.

[8] D. Brabie, "Wheel-sleeper impact model in rail vehicles analysis," Journal of System Design and Dynamics, vol. 1, no. 3, pp. 468-480, 2007.
[9] K. S. Song, S. H. Han, and Y. S. Choi, "Wheel/rail contact analysis considering friction and torque," in Proceedings of the Spring Conference of the Korean Society for Railway, KSR2013S073, pp. 447-452, Korean Society for Railway, Pyeongchang, Republic of Korea, May 2013, in Korean.

[10] P. D. Moyer, R. W. James, C. H. Bechara, and K. L. Chamberlain, Safety of High Speed Guided Ground Transportation Systems-Intrusion Barrier Design Study, Final Report: R5021/RR593, DOT-VNTSC-FRA-95-3, DOT/FRA/ ORD-95/04, U.S. Department of Transportation, Washington DC, USA, 1994.

[11] Railtrack PLC (Safety \& Standards Directorate), Recommendations for the Design of Bridges, Railtrack Approved Code of Practice, GC/RC5110, Railtrack PLC, London, UK, 2000.

[12] Network Rail (NR), Design of Bridges (Design Loading for Accommodation and Occupation Overbridges), NR/L3/CIV/020, Network Rail Kings Place, London, UK, 2011.

[13] R. H. Pfeifer and T. M. Molter, Handbuch Eisenbahnbrücken, DVV Media Group GmbH, Eurailpress, Hamburg, Germany, 2008, in German.

[14] Booz Allen Hamilton, Report on the Findings of: Current Practice and Effectiveness of Derailment Containment Provisions on High Speed Lines, Issue 1, Ref: R00673, HSL-Zuid Organisation, Zoetermeer, Netherland, 2004. 


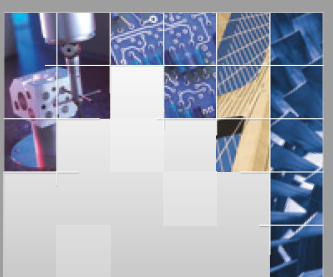

\section{Enfincering}
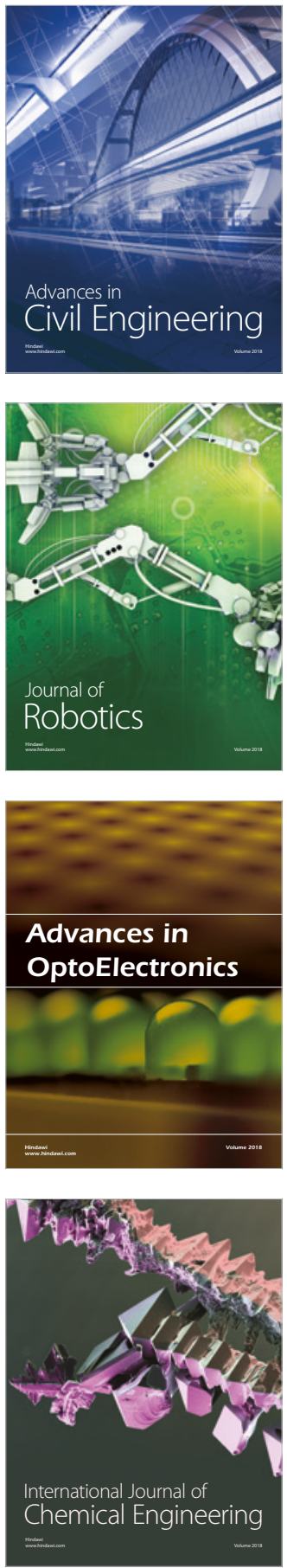

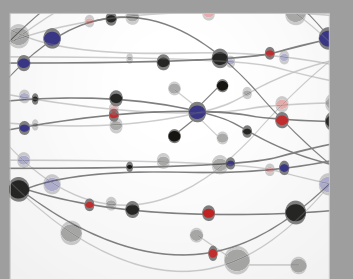

\section{Rotating \\ Machinery}

The Scientific World Journal

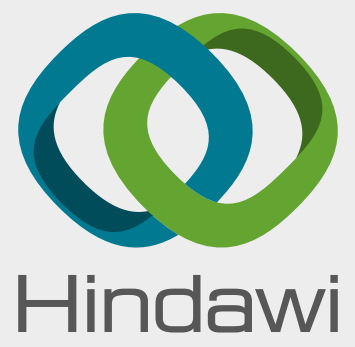

Submit your manuscripts at

www.hindawi.com
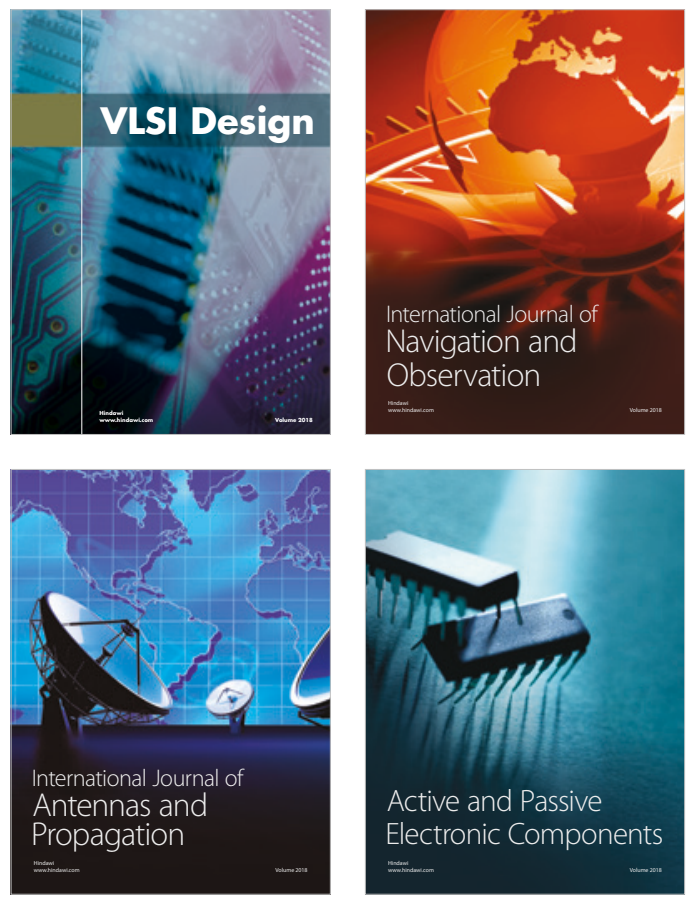
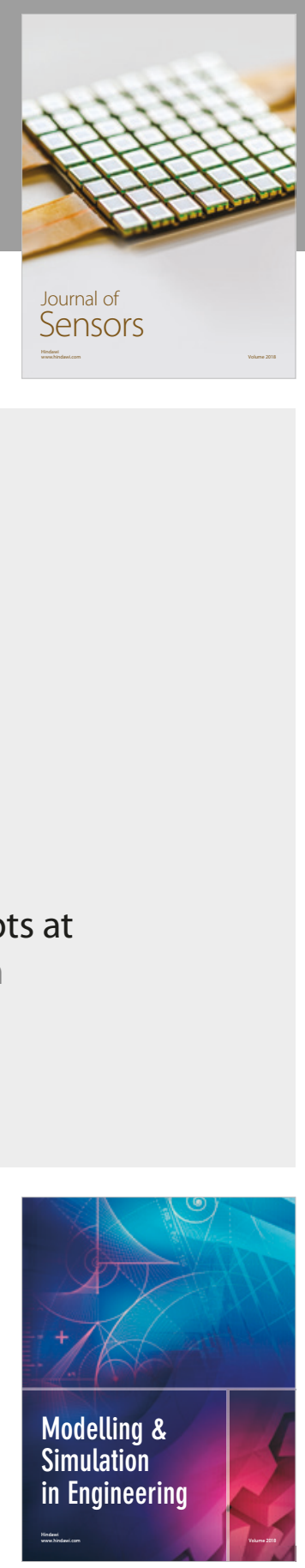

\section{Advances \\ Multimedia}
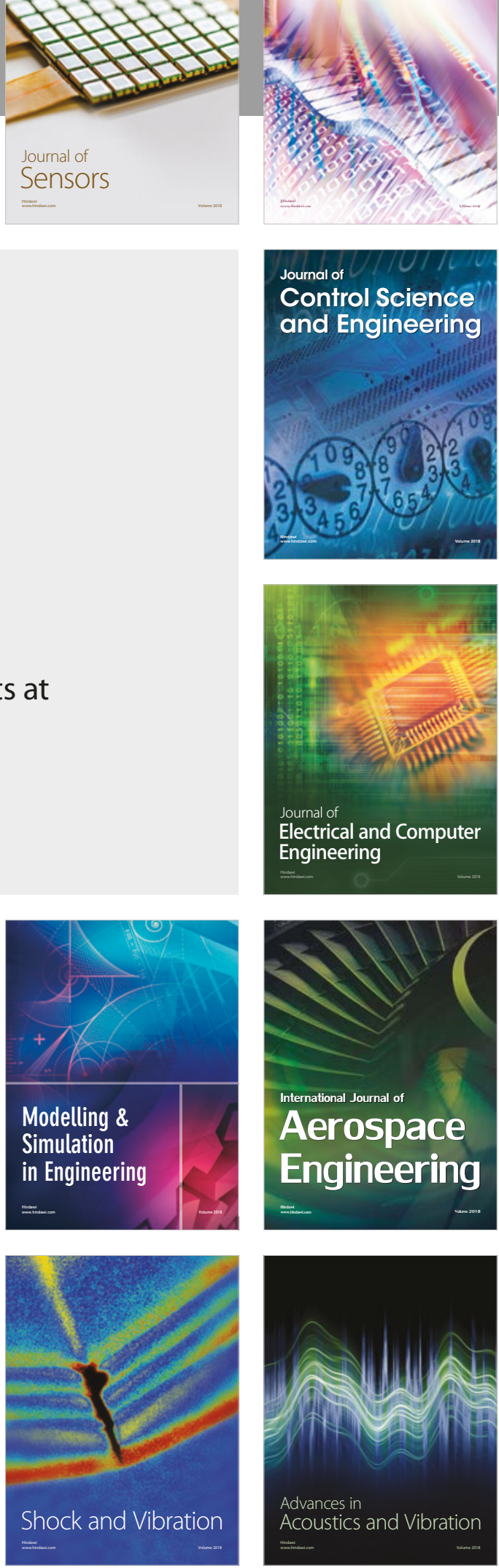